\title{
Neurological Teratogenic Effects of Anti-Epileptic Drugs During Pregnancy
}

\author{
Sarita Jangra Bhyan'1, Bhupinder Bhyan, ${ }^{2}$ Pankaj Singh Negi², Shubham Gangawat ${ }^{2}$, Paluck' ${ }^{2}$ Indradeep Yadav ${ }^{2}$ \\ ${ }^{1}$ Assistant Professor, Department of Pharmacy Practice, Teerthanker Mahaveer College of Pharmacy, TMU, Moradabad, UP, India. \\ 2. Pharm D, Deparment of Pharmacy Practice, Teerthanker Mahaveer College of Pharmacy, TMU, Moradabad, UP, India. \\ *Corresponding author's E-mail: sarita28787@gmail.com
}

Received: 10-06-2020; Revised: 19-08-2020; Accepted: 28-08-2020.

DOI: 10.47583/ijpsrr.2020.v64i01.010 ABSTRACT

Epilepsy is one of the few neurologic disorders that require a constant treatment during pregnancy. Prescription of anti-epileptic drugs (AEDs) to pregnant women with epilepsy requires monitoring and maintaining a balance between limiting seizures and decreasing fetal exposure to the potential teratogenic effects. AEDs are also commonly used for psychiatric disorders and migraines. The types of malformations that can result in fetuses exposed to AEDs include minor anomalies, major congenital malformations, intrauterine growth retardation, cognitive dysfunction, low $I Q$, microcephaly, and infant mortality. In the present review, we analysed and summarised the current understanding of neurological development in fetus that are exposed to various AEDs administered to pregnant epileptic women. Unfortunately, AED combinations were shown to yield only a relatively small gain in seizure control in patients with focal epilepsies if a potentially appropriate first drug has already failed. The logical possibility was therefore raised that combinations of AEDs with different molecular mechanisms of action might provide a better chance of seizure control than combinations of AEDs all of which possessed the same mechanism of action, for example on $\mathrm{Na}+$ channels, GABA -Cl or synaptic vesicle mechanisms, AMPA receptors. However, few studies are yet available demonstrating that this expectation applies in practice.

Keywords: Epilepsy, Teratogenicity, Seizures, Congenital malformations, AED Monotherapy, AED Polytherapy, Intrauterine growth, Anticonvulsants, Cognital Malformation.

\section{INTRODUCTION}

$\mathrm{E}$ pilepsy is the one of the most prevalent neurological disorder. Epilepsy in pregnancy could be more serious complication. Research studies suggested that child bearing women suffering from epilepsy have two to three folds more chances to find deformities in their offspring then normal pregnant women. ${ }^{1} \mathrm{All}$ though the mainstay therapeutic function of AEDs is to cure epilepsy but in clinical setting they have been used in Bipolar mood disorder, Migraine and various neuropathic pain. ${ }^{2}$ Statistical data for pregnant women taking AEDs shows $30 \%$ of maternal mortality and about $50 \%$ of foetal fatality. ${ }^{3}$ AEDs are also administered to pregnant epileptic patients; however, they have negative consequences to foetus. ${ }^{4}$ Therefore many pregnant women are exposed to the adverse effects of AEDs. As, AEDs are very important for the treatment of epilepsy, most of the women with epilepsy require AEDs to control seizures to entire period of pregnancy. The concerning problems with this situation is development of the Tonicclonic seizures, which may lead to the adverse effects to the foetus such as: intracranial hemorrhage, transient hemorrhage and heart beat abnormalities. ${ }^{5}$

Previous animal research studies have often explained association between high dosage of antiepilectic drugs and elevated teratogenic effects but in comparison to human subject it's not that much obvious finding. Although valproate and phenobarbital shows more chances of complications such as spina bifida and neural tube effects at high dosage. Numerous studies have suggested that VPA holds the highest neurodevelopment teratogenic upshot. ${ }^{4}$

There are many actions by which AEDs affect the foetal neural development. ${ }^{6}$ Numerous research studies have proved that old generation AEDs such as valproate, carbamazepine, phenytoin, phenobarbital clonazepam shows more dangerous teratogenic effects. ${ }^{6}$ For example valporate may be the reason behind spina bifida, phenytoin can cause digit hyperplasia, phenobarbital can lead to oral cleft while carbamazepine can cause neural tube effects. ${ }^{7}$ Studies found that AEDs have $6.1 \%$ chances of developing congenital malformation on pregnant women and malformation rate is different according to the AED. ${ }^{8}$

Its certitude that AEDs can-not be replaced and not be appropriate to renounced in pregnancy. This is concern which necessitates to be explicated on broadly. The challenges are to balance these risks and to select a therapy which is effective in preventing major seizures although minimizing adverse drug effects of foetal. ${ }^{9}$ Foetus expansion process surmount through three specific phases. 


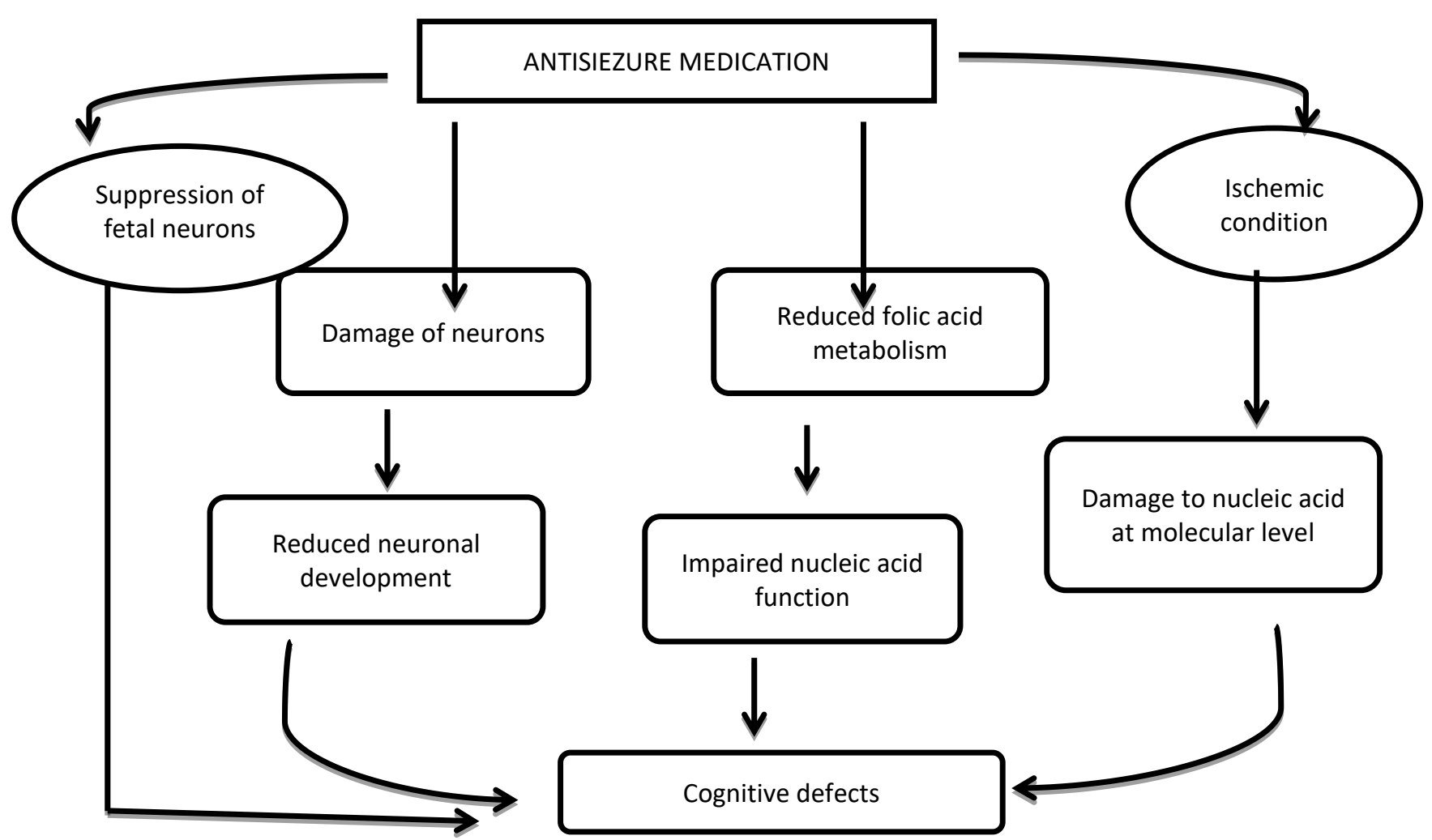

Figure 1: Cognitive Defects Process

Blastocyst formation Organogenesis Histogenesis
[0-16 days]
[17-60 days]
[after 60 days to full term]

Teratogenic agents mostly interrupt organogenesis phase of development.

Treatment options have increased but clarifying the Teratogenic potential of a new drug take a long time, In this review some AEDs which we are addressing are phenytoin, valproic acid, carbamazepine, phenobarbital, due to the fact that old generation AED's are most likely to lead Teratogenic effects than the new generation AED's. ${ }^{10}$

Pregnancy loss, Intra-uterine growth and Foetal anticonvulsant syndromes:

Women with epilepsy have the higher rate of spontaneous abortions. There is higher rate of abortion among women taking AEDs than among untreated women with epilepsy. The risk of abortion was higher with use of valproate about $8 \%$ than with other drugs, which is $1 \%$ with phenobarbital to $6 \%$ with lamotrigine. Prospective as well as retrospective data used by a centre study from 388 pregnancies in women with epilepsy, spontaneous abortions occurred in 39 women which are nearly $10 \%$. The rate was lower among women with folic acid supplementation about $6 \%$ than among those women without supplementation was $13 \%$, suggesting a protective effect of folic acid. ${ }^{11}$ However, because this was a non-randomized and partly retrospective study, the reported association cannot be taken as evidence of a prophylactic effect of folic acid. New-born babies with small head circumference was seen in increased proportion those who exposed to AED polytherapy or monotherapy as compared to new-born not exposed to any AED's, in uterus according to the population based studies. $^{12}$

Association between exposure to certain AEDs and dysmorphic features of the child is described by many investigators, sometimes in combination with major malformations and learning and behavioural problems. ${ }^{13}$ Such syndromes have been described in association with phenytoin, carbamazepine, and valproate. Findings from some reports suggest that the features of these syndromes are specific depending on the type of AED used by the mother. ${ }^{14}$

\section{MATERIALS AND METHODS}

This review is focused on Neurological Teratogenic effects of Anti-Epileptic Drugs during Pregnancy. Therefore PubMed (Medline), Elsevier, Cochrane and Google Scholar databases were searched using the terms 'Neurological Teratogenicity' or 'Anti-Epileptic Drugs during Pregnancy or Current Treatment Trends in AEDs'. Furthermore, we searched the currently available scientific literature.

\section{RESULTS}

\section{Foetal growth and health}

Those babies who are exposed to antiepileptic drug are found to be little premature, also affect gestational 
period and the babies are born underweight. ${ }^{15}$ Women with epilepsy have a higher risk of baby miscarriage. ${ }^{16}$ Those mothers who are exposed to the AED have a risk of physical deformities and however, a higher chance of birth defects to children.

\section{Congenital major malformations}

Malformation occurs due to drug detoxifying enzyme activity. Offspring has a higher risk of malformations when maternal is exposed to AED. There is no such statistical evidence of children suffering from malformation born to mother, who take epileptic drug. ${ }^{17}$ Major malformation occur due to combine drug or the polytherapy of carbamazepine, Phenobarbital and valproate whereas defects are seen due to monotherapy with valproate. ${ }^{16}$

\section{Neuro-behavioural endpoints}

Those children who are exposed to AED showed lower IQ than healthy children and this is due to inhibition of foetal brain development. When parental are exposed to AED, the momentary activity, attention, memory, emotion and autonomic control gets affected. ${ }^{18}$ Concluded in an experiment that mother exposed to the monotherapy can affect the left part of brain whereas polytherapy can affect the right part of the brain.

\section{Neural tube defect}

Neural tube defect is birth defect of the brain, spine or spinal cord. Usually, neural tube defect is lower in number but often tends to be very severe, they occur mainly between three-four weeks of gestational age. Valproate and Carbamazepine are directly related to neural tube defect. ${ }^{19}$

\section{Effect of Polytherapy and Monotherapy in Pregnancy}

When more than one medication is used, is known as polytherapy whereas when one medicine is used is known as monotherapy. It is found from some studies that effect of polytherapy is more than monotherapy. Table 1 has some reviews of some studies where debate between monotherapy and polytherapy can be concluded:-

Table 1: studies showing debate between monotherapy and polytherapy

\begin{tabular}{|c|c|c|}
\hline Researcher & Monotherapy & Polytherapy \\
\hline Qingemei Nie $(2016)^{3}$ & $3.7 \%$ & $6 \%$ \\
\hline E.Batttina Samren $(1999)^{20}$ & $4-6 \%$ & $3-30 \%$ \\
\hline William O Tantum (2006) & & \\
NAPR & $4.5 \%$ & $8.6 \%$ \\
UK & $3.7 \%$ & $6 \%$ \\
\hline Italy & $5.7 \%$ & $5.3 \%$ \\
\hline Torbzorn Tomson(2009) 22 & $4 \%$ & $6.8 \%$ \\
\hline Holmes $(2001)^{23}$ & $4.5 \%$ & $8.6 \%$ \\
\hline Kimford Meador $(2008)^{24}$ & $2.40-5.20 \%$ & $2.10-8.50 \%$. \\
\hline
\end{tabular}

Every drug shows some of adverse effects on the body. But teratogenic effects are adverse on the off spring and in Table 2 the percentage of AED drugs are given which were written in review literature.

Table 2: The percentage of AED drugs given.

\begin{tabular}{|c|c|c|c|c|}
\hline & Phenytoin & Valproate & Phenobarbital & Carbamazepine \\
\hline Neural Tube Defects 21 & --- & $1-2 \%$ & ---- & $0.5-1 \%$ \\
\hline Major Congenital Malformation ${ }^{25}$ & $9.1 \%$ & $11.1 \%$ & $5.1 \%$ & $5.7 \%$ \\
\hline Physical Malformations ${ }^{23}$ & $2.3 \%$ & ---- & $1.6 \%$ & $5.3 \%$ \\
\hline
\end{tabular}

Recommendations for the treatment of epilepsy in women of childbearing potential

Whenever possible optimization of treatment should be done before pregnancy and the effectiveness assessed before conception, by following these:

- Reassessment of the indication for treatment and consider gradual withdrawal of AEDs in women in remission for whom the risk of relapse is low and who are willing to take the risk.

- Selecting the most appropriate AED for the woman's type of epilepsy and that with the lowest teratogenic potential. Whenever possible valproate should be avoided if equally effective AEDs are available.

- Aim should be monotherapy with the appropriate AED and try out the lowest effective dosage, for controlling tonic-clonic seizures. Whenever possible, avoid doses of $700 \mathrm{mg} /$ day and above of valproate.
- The plasma concentration of the AED measured when the dose has been optimised. Treatment can be optimised during pregnancy by following doing these:

- Avoid withdrawal or changes of AEDs when pregnancy is already established. Risks generally outweigh possible gains.

- Monitoring treatment more closely than normal observation. Monitor plasma concentrations of lamotrigine in particular and possibly oxcarbazepine and levetiracetam.

- Adjust dose based on seizure control. Consider a dose increase also if there is a pronounced fall in AED plasma concentrations from optimum pre-pregnancy concentrations. $^{25}$

- Offer prenatal diagnosis 


\section{DISCUSSION}

\section{Neural Defects Caused by using different AEDs}

Various AEDs have been investigated due to their effect for teratogenicity in pregnant women. As we know the fact that AEDs cannot be discontinued during pregnancy, this becomes an issue that needs to be elaborated on extensively. The AEDs which we discuss in this review are Phenytoin, Valproate, Phenobarbital, Carbamazepine, Lamotrigine and Topiramate.

\section{Phenytoin}

Phenytoin is a derivative of hydantoin which can lead to 'fetal delantine syndrome/ phenytoin embryopathy/fetal hydantoin syndrome. ${ }^{26}$ This syndrome can lead to multifarious malformed finding namely epicanthal folds, orbital hypertelorism, head circumference, flat and broad bridge of nose, strabismus, ptosis wide lips and many more, consequently the teratogenicity of phenytoin has been acknowledged. ${ }^{7}$

\section{Valproate}

Multiple recent animal and human subject studies, epidemiologic studies and case studies established teratogenicity of valproic acid especially in the first trimester

of pregnancy. ${ }^{12}$ MultipleStudies explain that intrauterine valproate exposure is linked with changes in folic acid metabolism by obstructing key enzymes in folate metabolism pathway. It can lead to fetal valproate syndrome. Symptoms of this syndrome may such as distinctive facial dysmorphic features, musculoskeletal abnormalities cleft lips, autism, spina bifida, lower verbal $1 Q .{ }^{27}$

\section{Phenobarbital}

PHB is one of the oldest anticonvulsive drug. The effects of phenobarbital were not assessed on featus till 1970s. phenobarbital can lead to fallout tetralogy in heart, hydro-nephrosis, umblical or inguinal hernia, congenial dislocation of the hips, however various studies suggest that phenobarbital monotherapy do not show high degree of Teratogenic effects in comparison to other old generation AED's. Some studies elaborate that phenobarbital may produce superoxide radicals, which further form hydroxyl radicals, these radicals participate in conversion of GC into TA, this conversion ultimately lead to major congenital malformations. ${ }^{28}$

\section{Carbamazepine}

Carbamazepine is identified as human teratogen. Case studies suggested that when some childbearing epileptic women treated with CBZ monotherapy their fetal head periphery was $8-10 \mathrm{~mm}$ decrease in comparison to normal fetal head circumference, which did not develop normal by the age of $18-20$ months. ${ }^{29}$ CBZ causes major and minor deformities such as development issues, spastic IQ, and growth retardation.

\section{Lamotrigine}

Lamotrigine is a new drug as compared to other AEDs and therefore, there is lack of availability of much long term information available on its effects on foetus development. The data we have recognised that women on Lamotrigine present with Foetal malformation at a rate of $2.7 \%$ when compared to the general population which is nearly $1.6 \% .{ }^{3}$ Another data in UK shows that there is a dose-dependent effect on foetus. These two data confirming that there is increase occurrence of facial cleft.

\section{Topiramate}

The available data for Teratogenic effect of Topiramate is limited, as it is also used in the treatment of migraine. The types of topiramate resultingmal formation include oral clefts and hypospadias, which were 11- 14 fold higher. ${ }^{31}$ Hypospadias is a birth defect of urethra in male and multiple cases of this disorder have been reported for children that were exposed to Topiramate in uterus.$^{3}$ Studies also found that pregnant woman who were exposed to Topiramate have child of lower birth weight and as well as have a higher risk and rate of spontaneous abortions.

\section{CONCLUSION}

The risk for major malformations with use of carbamazepine and lamotrigine in monotherapy seems to be less, compared with the general population. Another study is showing significantly lower rates of malformation with exposure to carbamazepine and lamotrigine than with valproate and probably also than with phenobarbital, although the data is limited. we need a future analyses should include comparisons between the different AEDs and risks for specific malformations. Available data on the effects of AEDs on neurodevelopment are less described because most studies assessed children at a very early age. However, findings are consistent in that children exposed to valproate have more neurodevelopment problems than those exposed to carbamazepine or lamotrigine. There are challenges for us like assessment of the teratogenic mechanisms of AEDs and of individual susceptibility. In this review used data is from studies of women with epilepsy and Teratogenic risks in their off springs. It might be possible that similar analysis is seen when AEDs are used to treat different diseases during pregnancy like Migraine and psychiatric disorders.

Acknowledgements: First of all, we would like to express our heartiest gratitude towards Teerthankar Mahaveer College of Pharmacy for giving us a golden opportunity to work on this article. Special thanks to the Principal of Teerthankar Mahaveer College of Pharmacy, Prof.A.K. Ghosh for his support and vision.

Eventually we would like to thank all who directly or indirectly helped us out in preparing this article. 


\section{REFERENCES}

1. Torbjorn Tomson, Dina Battino. Crawford P. Best practice guidelines for the management of women with epilepsy. Epilepsia. 46, 2005, 117-124. DOI:10.1111/j.1528-1167.2005.00323.x

2. Teratogenic effects of antiepileptic drugs. Seizures. 17(2), 2008, 166-71. DOI:10.1016/S1474-4422(12)70103-5

3. Hill DS, Wlodarczyk BJ, Palacios AM, Finnell RH. Teratogenic effects of antiepileptic drugs. Expert Rev Neurother. 10, 2010, 943-959. DOI: $10.1586 /$ ern.10.57.

4. Qingmei Nie, Baohua Su, Jianping Wei.Neurological teratogenic effect of antiepileptic drugs during pregnancy. Experimental and Therapeutic Medicine. 12, 2016, 2400-2404. DOI: 10.3892/etm.2016.3628

5. Schmidt D, Canger R, Avanzini G, Battino D, Cusi C, BeckMannagetta G, Koch S, Rating D, Janz D. Change of seizure frequency in pregnant epileptic women.J Neurol Neurosurg Psychiatry. 46, 1983, 751-755. DOI:10.1136/jnnp.46.8.751

6. S. Kaneko, D. Battino, E. Andermann, K. Wada, R. Kan, A. Takeda, Y. Nakane, Y. Ogawa, G. Avanzini, C. Fumarola, T. Granata, F. Molteni, G. Pardi, L. Minotti, R. Canger, R. Canger, M. Oguni, I. Lopes-Cendas, A. Sherwin, F. Andermann, M.-H. Seni, M. Okada, T. Teranishi. Congenital malformations due to antiepileptic drugs. Epilepsy Research 33, 1999, 145-158. DOI:10.1212/wnl.62.1.28

7. Allen RW, Jr, Ogden B, Bentley FL, Jung AL. Fetal hydantoin syndrome, neuroblastoma, and hemorrhagic disease in a neonate. JAMA.(1980);244:1464-1465. 10.1001/jama.1980.0331013004202

8. Meador K, Reynolds MW, Crean S, Fahrbach K, Probst C. Pregnancy outcomes in women with epilepsy: a systematic review and metaanalysis of published pregnancy registries and cohorts. Epilepsy Res. 81, 2008, 1-13. DOI: 10.1016/j.eplepsyres.2008.04.022

9. Evan Gedzelman, Kimfored J Meador et al. Antiepileptic drug in women. Ther adv drug saf. 3(2), 2012, 71-78. DOI: 10.1212/wnl.62.1.28

10. Page B.Pennell. Antiepileptic drugs during pregnancy: What is known and which AEDs seem to be safest? Epilepsia. 49, 2008, 4345. DOI: 10.1111/j.1528-1167.2008.01926.x.

11. Dick lindhout, Julliette G.C Omtzigt. Teratogenic Effects of Antiepileptic Drugs: Implications for the Management of Epilepsy in Women of Childbearing Age.Epilepsia. 35(4), 1994, 19-28.DOI: 10.1111/j.1528-1157.1994.tb05952.x

12. Torbjorn Tomson, Dina Battino et al. Teratogenic effects of antiepileptic drugs. Lancet Neurol. 11(9), 2012, 803-13.DOI: 10.1016/S1474-4422(12)70103-5.

13. Adab N, Kini U, Vinten J, Ayres J, Baker G, Clayton-Smith J, Coyle H, Fryer A, Gorry J, Gregg J, et al. The longer term outcome of children born to mothers with epilepsy. J Neurol Neurosurg Psychiatry. 75, 2004, 1575-1583. DOI:10.1136/jnnp.2003.029132

14. Evan Gedzelman, Kimford J Meador. Antiepileptic drugs in Women With Epilepsy During Pregnancy.Ther Adv Drug Saf. 3(2), 2012, 7187. DOI: $10.1177 / 2042098611433192$

15. Leila Etemad, Mohammad Moshiri, Seyed Adel Moallem. Epilepsy drugs and effects on fetal development: Potential mechanism. J Res Med Sci. 17(9), 2012, 876-881. PMID: 23826017

16. F. J. E. Vajda,T. J. O’Brien,J. E. Graham,A. A. Hitchcock,C. M. Lander2,M. J. Eadie. Antiepileptic drug polytherapy in pregnant women withepilepsy. Neurologica. 138(3), 2018, 115-121. DOI: 10.1111/ane12965 PMID 29799623

17. Samre'n EB, van Duijn CM, Christiaens GCML, Hofman A, Lindhout D. Antiepileptic drug regimens and major congenital abnormalities in the offspring. Ann Neurol 46(5), 1999, 739-746.PMID: 10553991

18. E. Gaily Normal, EKantola-Sorsa,V.Hiilesmma, M.Ishoaho, R.Matila, M.kotila, T.Nylund, A.Bardy,E.Kaaja, M.L.Granstrom,.Intelligence in children with prenatal exposure to carbamazepine. Neurology. 62(1), 2004, 28-32. DOI:10.1212/wnl.62.1.28.PMID: 29799623

19. Emilio Perucca. An Introduction to Antiepileptic Drugs.Epilepsia 46(4), (2005), 31-37.DOI: 10.1111/j.1528-1167.2005.463007.x

20. E. Bettina Samren, Cornelia M. Van Duijn,G. C. M. Lieve Christiaens,Albert Hofman, Dick Lindhout. Antiepileptic drug regimens and major congenital abnormalities in the offspring. Annals of Neurology. 46(5), 2001, 739-746. DOI:10.1002/15318249(199911)46:5<739::AID-ANA9>3.0.CO;2-2

21. William O Tantum. Use of Antiepileptic Drugs in Pregnancy. Expert Rev Neurother. 6(7), 2006, 1077-86. DOI: $10.1586 / 14737175.6 .7 .1077$

22. Torbj „rn Tomson, Dina Battino. Teratogenic Effects of Antiepileptic Medications. Neurol Clin.C 27, 2009, 993-1002. DOI: 10.1016/j.ncl.2009.06.006

23. Lewis Holmes B, Elizabeth A, Harvey ,Brent A. Coull, Kelly B. Huntington, Shahram Khoshbin, Ailish M. Hayes, and Louise M. Ryan. The teratogenicity of anticonvulsantdrugs.N Engl J Med. 344, 2001, 1132-1138. DOI: 10.1056/NEJM200104123441504

24. KimfordMeador , Matthew W.Reynolds, Sheila Crean,Kyle Fahrbach,Corey Probst.Pregnancy outcomes in women with epilepsy: A systematic review and meta-analysis of published pregnancy registries and cohorts. Epilepsy res. 81(1), 2008, 1-13. DOI: $10.1016 /$ j.eplepsyres.2008.04.022

25. Caroline Nadebaum, Vicki Anderson, Frank Vajda, David Reutens, Amanda Wood. Neurobehavioral Consequences of Prenatal Antiepil eptic Drug Exposure. Dev Neuropsycol. 37(1), 2012, 1-29. DOI: 10.1080/87565641.2011.589483.

26. Adams J, Vorhees CV, Middaugh LD. Developmental neurotoxicity of anticonvulsants: human and animal evidence on phenytoin. Neurotoxicol Teratol. 12, 1990, 203-214 DOI: $10.1016 / 0892-0362(90) 90092-Q$

27. Alexander Semmler,Christian Frisch,Christiane Bleul,Desiree Smith, Laurent Bigler, Jean-Christophe Prost, Henk Blom, Michae Linnebank. Intrauterine valporate exposure is associated with alterations in hippocampal cell numbersand folate metabolism in a rat model of valporate teratogenicity. Seizure. 46, 2017, 7-12. DOI:10.1016/j.seizure.2017.01.003

28. Walker BE, Patterson A. Induction of cleft palate in mice by tranquilizers and barbiturates. Teratology. 10(2), 1974, 159-163. DOI: 10.1002/tera.1420100212.

29. Harding JJ, Timko JV. The use of psychotropic medications during pregnancy and lactation. The Foundation for the Global Library of Women's Medicine. (2008), (ISSN1756-2228). DOI: 10.3843/GLOWM.10416

30. Hunt S, Russell A, Smithson WH, Parsons L, Robertson I, Waddell R, Irwin B, Morrison PJ, Morrow J, Craig J. UK Epilepsy and Pregnancy Register: Topiramate in pregnancy: preliminary experience from the UK Epilepsy and Pregnancy Register. Neurology. 71, 2008, 272-276. DOI: 10.1212/01.wnl.0000318293.28278.33.

Source of Support: None declared.

Conflict of Interest: None declared.

For any question relates to this article, please reach us at: editor@globalresearchonline.net New manuscripts for publication can be submitted at: submit@globalresearchonline.net and submit_ijpsrr@rediffmail.com 